\title{
Gallic Acid Induces Apoptosis in Human Gastric Adenocarcinoma Cells
}

\author{
CHUNG-LIN TSAI ${ }^{1,2 *}$, YING-MING CHIU ${ }^{3,4^{*}}$, TIN-YUN HO ${ }^{5}$, CHIN-TUNG HSIEH ${ }^{6}$, \\ DONG-CHEN SHIEH ${ }^{4}$, YI-JU LEE ${ }^{7}$, GREGORY J. TSAY ${ }^{8,9}$ and YI-YING WU ${ }^{10}$ \\ ${ }^{1}$ Division of Cardiovascular Surgery, Taichung Veterans General Hospital, Taichung, Taiwan, R.O.C.; \\ ${ }^{2}$ Graduate Institute of Clinical Medical Science, China Medical University, Taichung, Taiwan, R.O.C.; \\ ${ }^{3}$ Division of Allergy, Immunology \& Rheumatology, Changhua Christian Hospital, Changhua, Taiwan, R.O.C.; \\ ${ }^{4}$ Department of Nursing, College of Medicine \& Nursing, Hungkuang University, Taichung, Taiwan, R.O.C.; \\ ${ }^{5}$ Graduate Institute of Chinese Medicine, China Medical University, Taichung, Taiwan, R.O.C.; \\ ${ }^{6}$ Department of Pediatrics, Lotung Poh-Ai Hospital, I-Lan, Taiwan, R.O.C.; \\ ${ }^{7}$ Institute of Biochemistry, Microbiology and Immunology, \\ Chung Shan Medical University, Taichung, Taiwan, R.O.C.; \\ ${ }^{8}$ Division of Immunology and Rheumatology, Department of Internal Medicine, \\ China Medical University Hospital, Taichung, Taiwan, R.O.C.; \\ ${ }^{9}$ School of Medicine, College of Medicine, China Medical University, Taichung, Taiwan, R.O.C.; \\ ${ }^{10}$ Department of Medical Laboratory Science and Biotechnology, \\ China Medical University, Taichung, Taiwan, R.O.C.
}

\begin{abstract}
Background/Aim: Gastric cancer is one of the most common malignant cancers with a poor prognosis and high mortality rate worldwide. Current treatment of gastric cancer includes surgery and chemotherapy as the main modalities, but the potentially severe side-effects of chemotherapy present a considerable challenge. Gallic acid is a trihydroxybenzoic acid found to exert an anticancer effect against a variety of cancer cells. The purpose of this study was to determine the anti-cancer activity of Galla chinensis and its main component gallic acid on human gastric adenocarcinoma cells. Materials and Methods: MTT assay and cell death ELISA were used to determine the apoptotic effect of Gallic Chinensis and gallic acid on human gastric adenocarcinoma cells. To determine the pathway and relevant components by which gallic acidinduced apoptosis is mediated through, cells were transfected with siRNA (Fas, FasL, DR5, p53) using
\end{abstract}

*These Authors contributed equally to this work.

Correspondence to: Yi-Ying Wu, Department of Medical Laboratory Science and Biotechnology, China Medical University, No. 91, HsuehShih Rd., Taichung 404, Taiwan, R.O.C. Tel: +886 422053366, ext. 7228, Fax: +886 422057414, e-mail: yyw@mail.cmu.edu.tw

Key Words: Gastric cancer, gallic acid, apoptosis, human gastric adenocarcinoma cell line, cytochrome $\mathrm{c}$.
Lipofectamine 2000. Reults: Gallic Chinensis and gallic acid induced apoptosis of human gastric adenocarcinoma cells. Gallic acid induced up-regulation of Fas, FasL, and DR5 expression in AGS cells. Transfection of cells with Fas, FasL, or DR5 siRNA reduced gallic acid-induced cell death. In addition, p53 was shown to be involved in gallic acidmediated Fas, FasL, and DR5 expression as well as cell apoptosis in AGS cells. Conclusion: These results suggest that gallic acid has a potential role in the treatment of gastric cancer.

Gastric cancer is the fifth most common cancer and is the third leading cause of cancer death worldwide (1). Standard treatment for advanced gastric cancer is hemotherapy based on fluoropyrimidines, administered alone or in combination, such as with 5-fluorouracil (FU), capecitabine, and S-1 (2). Although use of chemotherapy together with two targeted agents trastuzumab and ramucirumab have contributed to prolongation, overall survival for patients with advancedstage disease remains poor (2). Recently, several biomarkers of gastric cancer have also been studied in Taiwan, including critical protein cyclin D1 (CCND1) (3), interleukin-10 (4), DNA double strand break gene $\mathrm{Ku} 70$ (5), and DNA repair gene xeroderma pigmentosum group D (XPD) (6). However, these mechanisms still need further exploration and confirmatory research. Therefore, it is urgent to design novel therapeutic candidates to improve the efficacy of gastric cancer treatment. 
Chinese traditional herbal medicines are increasingly being used in the clinical setting and a number of promising plant-derived medicines for the treatment of cancer have emerged in recent years (7). In this study we investigated the application of a naturally-occurring substance as an adjuvant therapy in the treatment of gastric cancer.

Apoptosis is an intracellular suicide program possessing morphologic characteristics and biochemical features, including chromatin condensation, nuclear DNA fragmentation, cell shrinkage, membrane blebbing, and the formation of apoptotic bodies $(8,9)$. Apoptosis is a physiological mechanism for eliminating malignant cells or cancer cells without causing damage to normal cells or surrounding tissues. Thus, the induction of apoptosis in target cells is a key mechanism by which anticancer therapy works. Two major apoptotic pathways have been described, which are the extrinsic death receptor-mediated pathway and the intrinsic mitochondrioninitiated pathway. The extrinsic apoptotic pathway originates at membrane death receptors (DRs) such as Fas, DR4, and DR5, and then engages the intracellular apoptotic machinery involving adaptor molecules and proximal caspase- 8 as well as distal executioner caspases (10).

p53 is a proapoptotic gene (11). It has been reported that p53 triggers apoptosis through both DR and mitochondrial apoptotic pathways (12). DRs such as DR4, DR5, and Fas are increased by $\mathrm{p} 53$-dependent transcriptional activation (13). Interaction of tumor necrosis factor-related apoptosisinducing ligand (TRAIL), a member of the tumor necrosis factor family, with DR4 and DR5 leads to recruitment of the adaptor protein FADD and initiator caspase- 8 to the death inducing signaling complex (14). This results in enzymatic activation of caspase- 8 , which in turn activates a downstream caspase cascade in the presence or absence of mitochondrial amplification machinery (14).

Gallic acid (3,4,5-trihydroxybenzoic acid) is widely used as an antioxidant in the food industry and has been shown to exhibit a variety of pharmacological and biological activities, including anti-cancer, anti-bacterial, anti-viral, antiinflammatory, and antioxidant properties (15-25). Gallic acid is abundant in natural plants such as grapes, green tea, strawberries, pineapples, bananas, lemons, witch hazel, tea leaves, oak bark, and Galla chinensis, which is a traditional Chinese herb (24, 26-29). Gallic acid induces apoptosis in various cancer cell lines $(22,30-32)$ and helps to protect human cells against oxidative damage by exerting anticancer activity without harming healthy cells $(33,34)$. Although the anti-cancer properties of gallic acid have been demonstrated, its effects on human gastric adenocarcinoma remain largely undefined. This study is the first to attempt to determine the apoptotic activity of gallic acid in human gastric adenocarcinoma cell line. Our data provide evidence that gallic acid reduced cell survival via apoptosis when applied to human gastric adenocarcinoma cells.

\section{Materials and Methods}

Plant materials. The Galla chinensis used in this study was purchased from a local traditional Chinese medicine apothecary in Taichung, Taiwan. The plant material was identified by Nien-Yung Chiu, a technical specialist at the Institute of Chinese Pharmaceutical Sciences, and was subjected to thin-layer chromatography (TLC) analysis according to the protocol provided by the Pharmacopoeia Commission of the People's Republic of China (ChPC, 2000). The voucher specimen has been deposited in the Institute of Chinese Pharmaceutical Sciences, China Medical University.

Extraction and fractionation of Galla chinensis. Dried Galla chinensis $(100 \mathrm{~g})$ was extracted with $70 \%$ acetone by percolation until complete exhaustion. The Galla chinensis extract (GCE) was concentrated under reduced pressure at a temperature of less than $40^{\circ} \mathrm{C}$, divided into small aliquots, and kept at $-30^{\circ} \mathrm{C}$ until further use. The dry Galla chinensis yield was $68.9 \%$ (w/w). The GCE was suspended in distilled water and then partitioned with three different solvents (chloroform, ethyl acetate, n-butanol) to yield chloroform, ethyl acetate, n-butanol, and aqueous fractions, respectively. Each fraction was concentrated under reduced pressure at a temperature of less than $40^{\circ} \mathrm{C}$, and the solid mass was then dissolved in acetone, divided into small aliquots, and kept at $-30^{\circ} \mathrm{C}$ until use.

Antibodies and chemicals. Horseradish peroxidase-conjugated antimouse and anti-rabbit IgG, and rabbit polyclonal antibodies specific for Fas, FasL, TRAIL, DR4, DR5, p53, caspase-8, caspase-3, caspase-7, caspase-9, and PARP were purchased from Santa Cruz Biotechnology (Santa Cruz, CA, USA). All other chemicals were obtained from Sigma-Aldrich (St. Louis, MO, USA).

Cell culture. We used human peripheral blood mononuclear cells (PBMCs) and human gastric adenocarcinoma cell model system, AGS cells (ATCC CRL 1739). PBMCs were isolated using a modification of a previously described technique (35).

Western blot. For immunoblotting, proteins were boiled for $5 \mathrm{~min}$ in SDS sampling buffer (100 mM Tris-HCl, pH6.8, 4\% SDS, $0.2 \%$ bromophenol blue, $20 \%$ glycerol), separated by $12 \% \sim 15 \%$ SDSPAGE, then transferred to a nitrocellulose membrane. The membrane was blocked with $5 \%$ milk in TBS $(10 \mathrm{mM}$ Tris- $\mathrm{HCl}, \mathrm{pH} 7.6,150$ $\mathrm{mM} \mathrm{NaCl})$ for at least $1 \mathrm{~h}$. After washing with TBST (10 mM Tris$\mathrm{HCl}, \mathrm{pH} 7.4,0.9 \% \mathrm{NaCl}, 0.2 \%$ Tween 20 ) twice, the membrane was incubated with indicated primary $\mathrm{Abs}$ at $4{ }^{\circ} \mathrm{C}$ overnight. Unbound Abs were washed away by TBST three times for 5 min each time. Bound Abs were revealed with horseradish peroxidase (HRP)conjugated secondary Abs (anti-mouse or rabbit $\operatorname{IgG}$ ) diluted in blocking buffer (1:5,000 dilution) for $1 \mathrm{~h}$ at room temperature. Following washing in TBST three times for $10 \mathrm{~min}$ each time, the membrane was developed using the ECLTM system (Amersham Biosciences, Arlington Heights, IL, USA).

The cell lysate of cells exposed at different time points was run on SDS-PAGE and western blotting transferred to nitrocellulose membranes. Activation of caspase-3, caspase-8, caspase-9, Bcl-2, PARP, Cyt c, Bad, Bak, p53, Fas stimulation was detected with specific Antibodies (all from Santa Cruz, BioLegend, Cell Signaling Thermo, BD Pharmingen, and Cell Signaling) to identify the activation of these apoptotic family members by western blotting. 
Apoptosis assay. An ELISA (Cell Death Detection ELISA ${ }^{\text {PLUS, }}$ Roche Mannheim Biochemicals, Mannheim Germany) which detects cytoplasmic histone-associated DNA fragments was performed as previously described (36). Briefly, $1 \times 10^{4}$ AGS cells were cultured in a 96-well plate overnight, then treated with gallic acid, harvested by centrifugation at $200 \mathrm{~g}$ after $0,24,48,72 \mathrm{~h}$. The cells were lysed and the supernatant was collected and incubated with immunoreagent preprepared for $2 \mathrm{~h}$. After washed gently, the supernatant was pipetted into each well with a substrate solution and kept in the dark until development of the color was sufficient for photometric analysis. The reaction was determined in a spectrophotometer at $405 \mathrm{~nm}$.

MTT assay. Cell viability was determined by 3-[4,5-dimethylthiazol2-yl]-2,5 diphenyltetrazoliumbromide (MTT) assay. After treatment with gallic acid for $48 \mathrm{~h}$, cultures were treated with MTT $(0.5 \mathrm{mg} / \mathrm{ml})$ to each well and incubated for $2 \mathrm{~h}$ at $37^{\circ} \mathrm{C}$. Culture medium was then replaced with an equal volume of DMSO to dissolve formazan crystals. After shaking at room temperature for $5 \mathrm{~min}$, absorbance of each well was determined at $570 \mathrm{~nm}$ using a microplate reader (Bio-Tek, Winooski, VT, USA)

Histology. Cells were fixed with $95 \%$ alcohol for $30 \mathrm{~min}$. Then 1-2 $\mathrm{ml}$ of Wright-Giemsa stain was added. After $1 \mathrm{~min}$, an equal volume of deionized water or phosphate buffer, $\mathrm{pH}$ 6.8-7.2, was added. After 1-3 min, cells were thoroughly rinsed with deionized water and air-dried. Morphologic changes and changes in cell number were observed by bright-field microscopy.

siRNA transfection. siRNA against human Fas, FasL, DR5, p53, and control siRNA was purchased from Santa Cruz Biotechnology. Cells were transfected with siRNA (at a final concentration of $2 \mu \mathrm{g} / \mathrm{ml}$ ) using Lipofectamine 2000 (Invitrogen Life, Carlsbad, CA, USA) according to the manufacturer's instructions.

Statistical analysis. Statistical analyses of the data were performed with the SPSS 12.0 software. Data were analyzed using one-way analysis of variance (ANOVA) with PRISM 4.0 (GraphPad Software Inc., San Diego, CA, USA). $p<0.05$ was considered statistically significant in all comparisons.

\section{Results}

Galla chinensis induced apoptosis of human gastric adenocarcinoma cells. To investigate the potential of Chinese herb Galla chinensis (Figure 1A) to induce cell death, we first examined the effect of Galla chinensis on cell survival in human gastric adenocarcinoma cells (AGS cells) using the MTT assay. Treatment of cells with $0.4 \mathrm{mg} / \mathrm{ml}$ Galla chinensis for 48 or $72 \mathrm{~h}$ induced cell death in AGS cells, but not human peripheral blood mononuclear cells (PBMCs) (Figure 1B and C). According to a previous study, Galla chinensis inhibits the growth of k562 cells (37), which was verified consistent with our findings, as seen in Figure 1D. We next investigated whether Galla chinensis induces cell death through an apoptotic mechanism using cell death ELISA. Treatment resulted in an increased concentration of apoptotic fragments over time, indicating the occurrence of apoptosis (Figure 1E).
Gallic acid induced apoptosis of human gastric adenocarcinoma cells. The main component of Galla chinensis is gallic acid (38), therefore we set out to investigate the potential for gallic acid (Figure 2A) to induce cell death of human gastric adenocarcinoma cells. Treatment of cells with $5 \mu \mathrm{M}$ gallic acid for 48 or $72 \mathrm{~h}$ induced cell death in AGS cells but not PBMCs (Figure 2B and C). In order to confirm a previous finding that showed gallic acid inhibiting the growth of k562 cells (37), we treated k562 cells with gallic acid and assessed cell survival via MTT (Figure 2D). The cell survival rate dropped to below $30 \%$ after $24 \mathrm{~h}$ of treatment, which was in line with the previous finding (37). We next investigated whether gallic acid induces cell death through an apoptotic mechanism using cell death ELISA. Treatment with a low concentration $(5 \mu \mathrm{M})$ of gallic acid resulted in an increased concentration of apoptotic fragments over time, indicating the occurrence of apoptosis (Figure 2E). We also observed the change in cell morphology and number via brightfield microscopy. As shown in Figure 2F, AGS cells decreased in number and became smaller and rounder over time. These data suggest that gallic acid induces cell death in gastric adenocarcinoma cells via an apoptotic mechanism.

Gallic acid-induced apoptosis in human gastric adenocarcinoma cells is mediated through the intrinsic pathway. We next assessed the pathway by which gallic acid mediates apoptosis in gastric adenocarcinoma cells. Figure $3 \mathrm{~A}$ shows that caspase- 8 expression increased in a timedependent manner, while the activation of pro-caspase- 8 was significantly reduced. In contrast, expression of caspase- 3 and caspase-9 increased with time as shown in Figure 3B and $\mathrm{C}$. The preliminary results show that the apoptosis of AGS cells caused by gallic acid is mediated by the caspase family. PARP, which is a known hallmark of cell death through an apoptotic pathway, also significantly increased, as shown in Figure 3B. In addition, expression of antiapoptotic proteins in the Bcl-2 family were reduced and expression of mitochondrial small protein molecules such as $\mathrm{Bad}, \mathrm{Bak}$, and cyt c increased in AGS cells (Figure 3C). These results indicate that gallic acid mediates apoptosis of gastric adenocarcinoma cells through the intrinsic pathway. Based on the results of the above experiments (Figure 3AC), we verified this finding by treating AGS cells with a pancaspase inhibitor (Figure 3D). Gallic acid was not capable of causing death of AGS cells following the addition of a pancaspase inhibitor.

Fas, FasL, and DR5 up-regulation are mediated by gallic acid-induced cell apoptosis in human gastric adenocarcinoma cells. Because gallic acid induced the cleavage of initiator caspase-8, we speculated that its proapoptotic response could be mediated via the death receptor-signaling pathway. As 
A<smiles>CC(=O)C(C)C(=O)c1cc(O)c(O)c(O)c1</smiles>

B

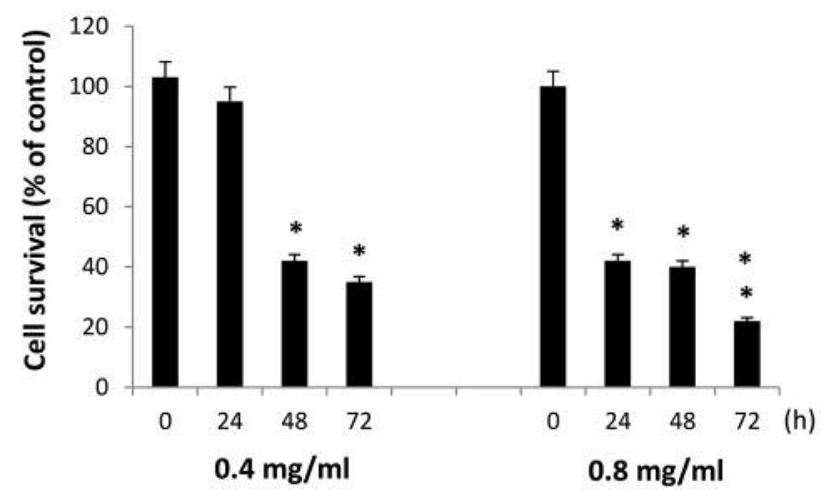

C

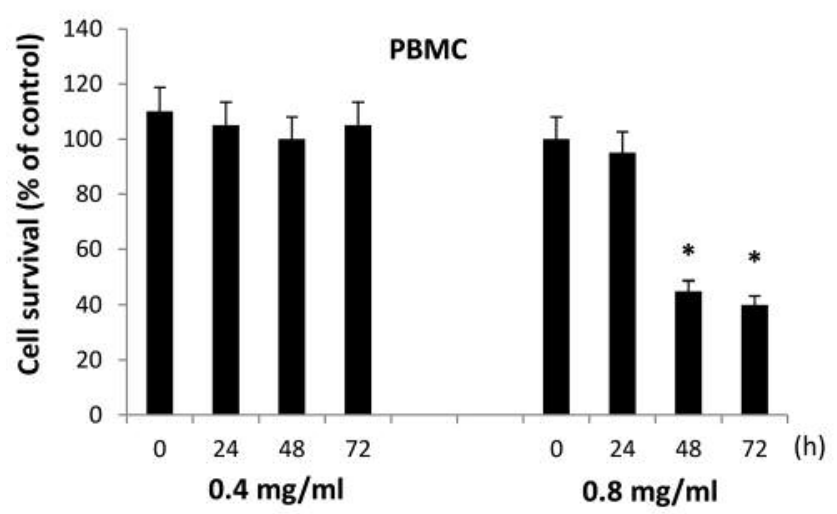

D

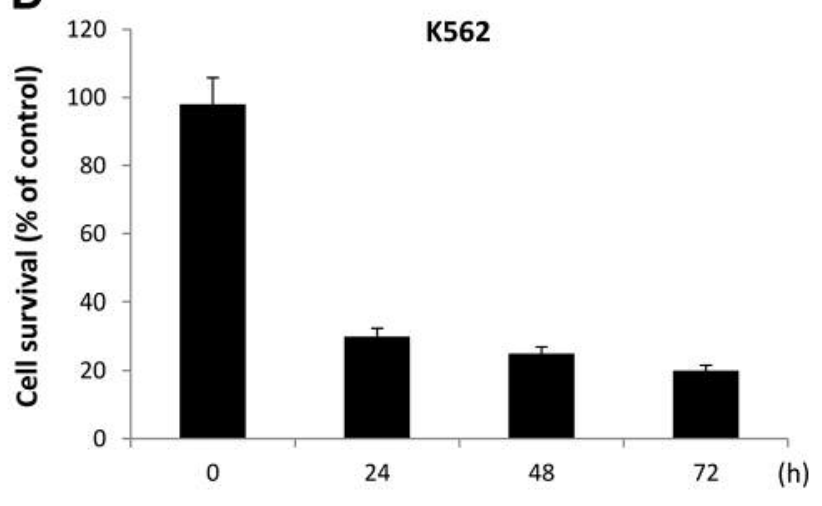

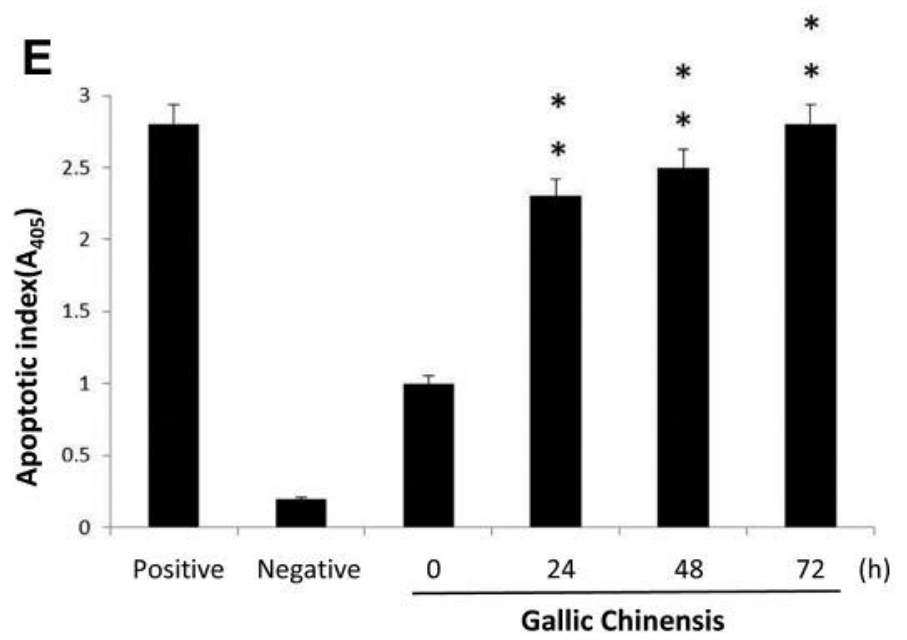

Figure 1. The influence of Chinese herbal medicine Galla chinensis on the growth of human gastric adenocarcinoma cells. (A) Galla chinensis contains $50 \%$ to $70 \%$ hydrolysable tannin which yields gallic acid. (B) Cytotoxicity of Galla chinensis in AGS cells. Cells were exposed to the compound $(0.4 \mathrm{mg} / \mathrm{ml}$ and $0.8 \mathrm{mg} / \mathrm{ml})$ for various lengths of time $(0,24,48,72 \mathrm{~h})$ followed by analysis using an MTT assay. All assays were performed in triplicate. ${ }^{*} p<0.05 ;{ }^{*} p<0.01$ compared to control. (C) Cytotoxicities of Galla chinensis in PBMCs. Cells were exposed to the compound $(0.4 \mathrm{mg} / \mathrm{ml}$ and $0.8 \mathrm{mg} / \mathrm{ml})$ for various lengths of time $(0,24,48,72 \mathrm{~h})$ followed by analysis using an MTT assay. All assays were done in triplicate. ${ }^{*} p<0.05 ;{ }^{*} p<0.01$ compared to control. (D) Effect of Galla chinensis on cell survival of K562. The cells were incubated with Galla chinensis $(0,24,48,72 \mathrm{~h})$ and the cell viability was examined by MTT assay. All assays were done in triplicate. ${ }^{*} p<0.05 ; * * p<0.01$ compared to control. (E) Induction of apoptosis in AGS cells by Galla chinensis treatment. Cells were exposed to gallic acid for various lengths of time: 0, 24, $48,72 \mathrm{~h}$ by cell death ELISA. All assays were done in triplicate. ${ }^{*} p<0.01$ compared to control. 
A<smiles>O=C(O)c1cc(O)c(O)c(O)c1</smiles>

B

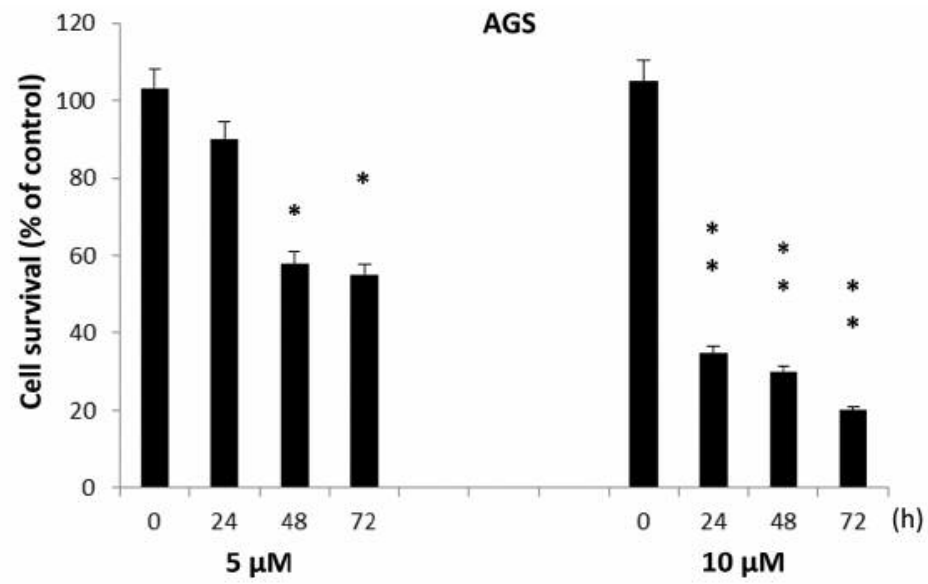

C

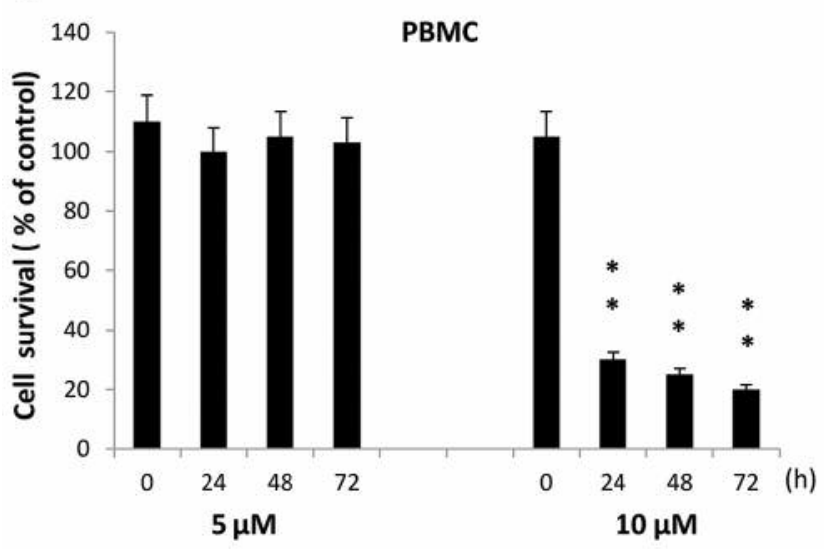

D

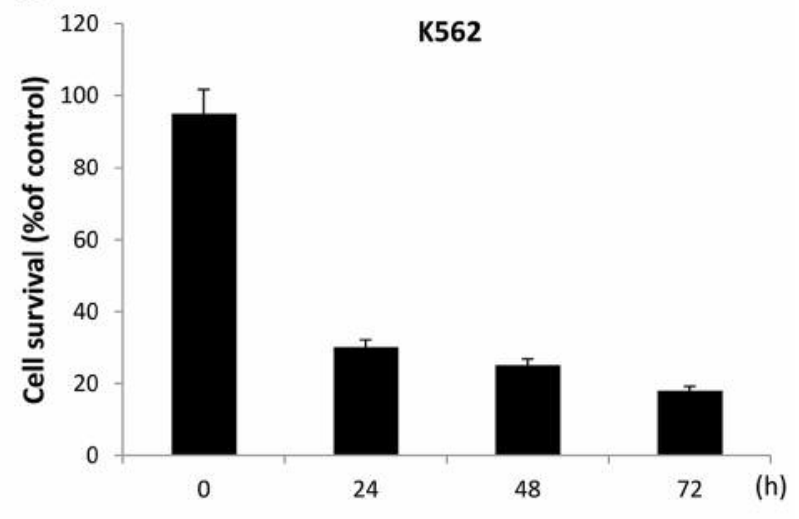

E

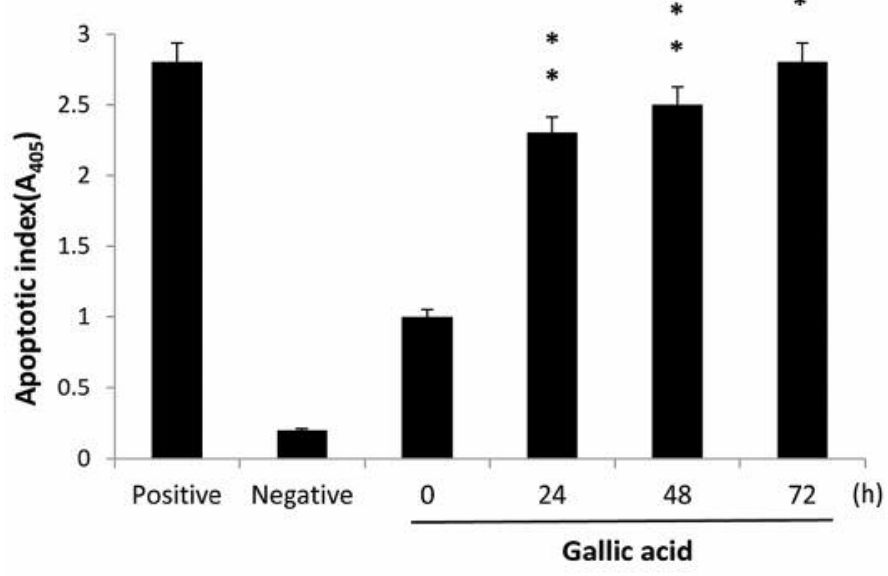

F

$\mathbf{O h}$

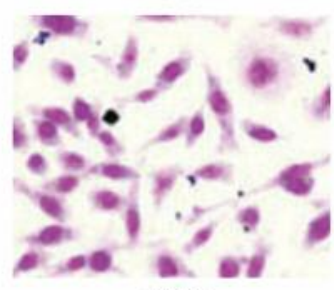

$48 \mathrm{~h}$

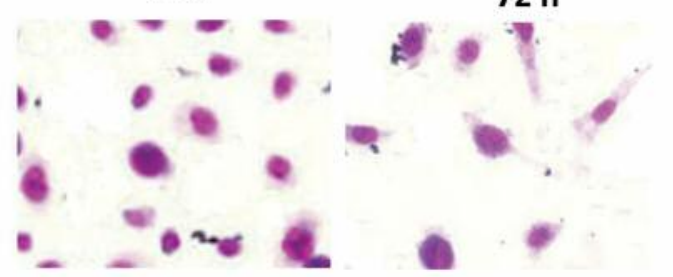

Figure 2. Induction of apoptosis in human gastric adenocarcinoma cells by gallic acid treatment. (A) Chemical structure of gallic acid. (B) Cytotoxicities of gallic acid in AGS cells. Cells were exposed to the compound $(0 \mu \mathrm{M}$ and $5 \mu \mathrm{M})$ for various lengths of time $(0,24,48,72 \mathrm{~h})$ followed by analysis using an MTT assay. All assays were performed in triplicate. ${ }^{*} p<0.05 ; * *<0.01$ compared to control. (C) Cytotoxicities of gallic acid in PBMCs. Cells were exposed to the compound $(0 \mu \mathrm{M}$ and $5 \mu M)$ for various lengths of time $(0,24,48,72 h)$ followed by analysis using an MTT assay. All assays were done in triplicate. ${ }^{*} p<0.05 ; * * p<0.01$ compared to control. (D) Effect of gallic acid on the proliferation of K562 cells. The cells were incubated with gallic acid $(0,24,48,72 \mathrm{~h})$ and the cell viability was examined by MTT assay. $* p<0.05 ; * * p<0.01$ compared to control. (E) Induction of apoptosis in AGS cells by gallic acid treatment. Cells were exposed to gallic acid for various lengths of time: 0, 24, 48, 72 h by cell death ELISA. All assays were performed in triplicate. ${ }^{*} p<0.01$ compared to control. $(F)$ The morphological changes of AGS cells after gallic acid treatment. Cells were treated with various concentrations of gallic acid for 0, 24, 48, and $72 \mathrm{~h}$. Images were captured at 400x magnification. 
A

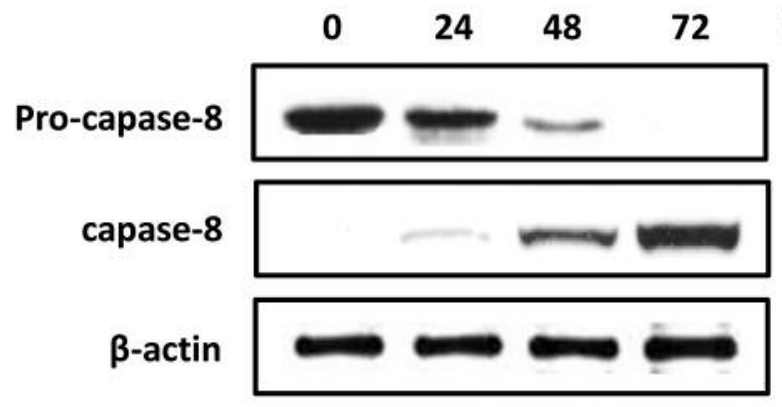

C

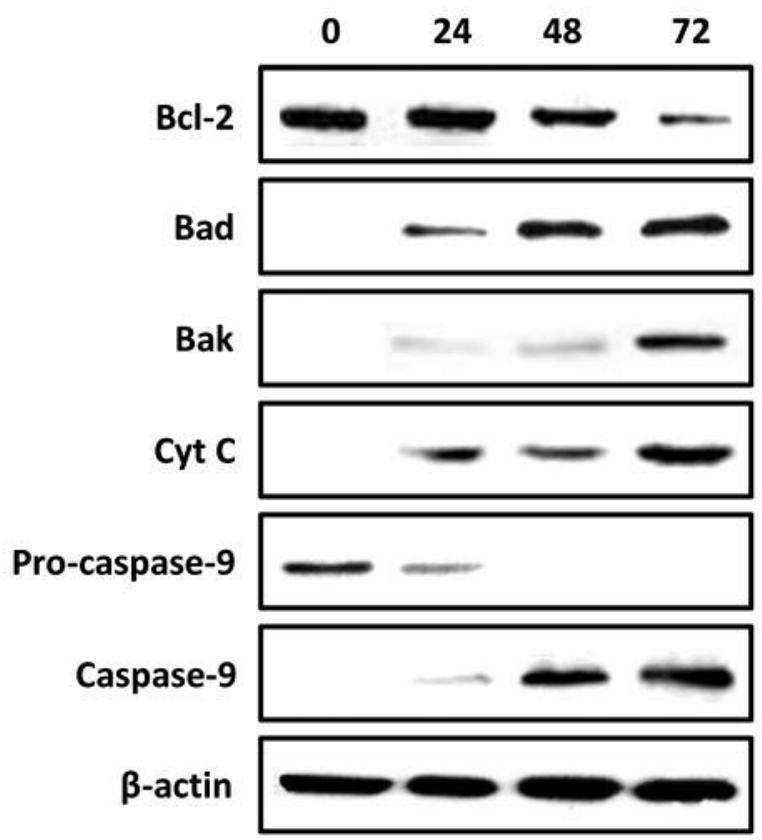

B

(h)

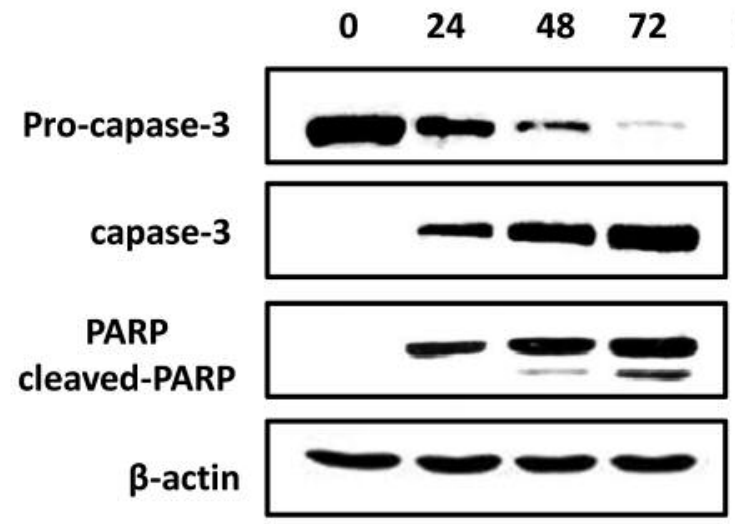

D

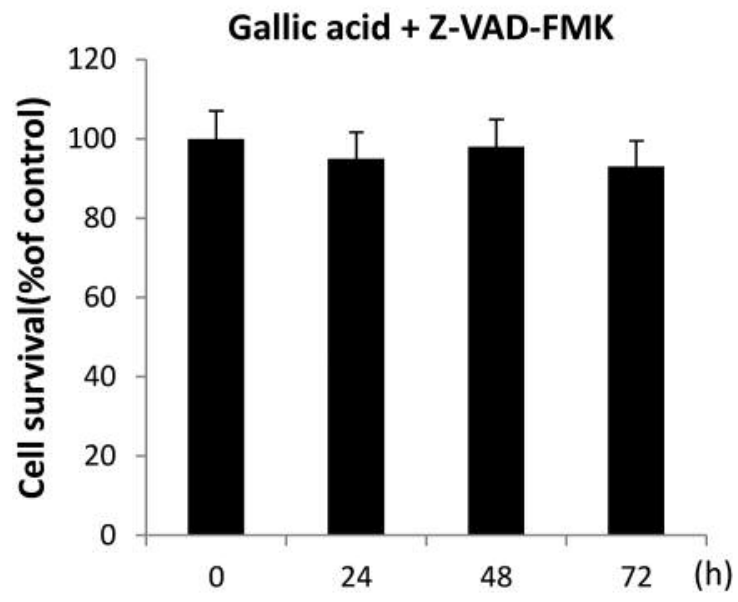

Figure 3. The path of gallic acid-induced apoptosis in human gastric adenocarcinoma cells. Effect of gallic acid on the expression of (A) caspase-8, pro-caspase-8 proteins, (B) caspases-3, pro-caspases-3, PARP, Cleaved PARP, (C) Cyt c, Bad, Bak, Pro-capase-9, capase-9, and Bcl-2in AGS cells . Cells were treated with gallic acid $(0-72 \mathrm{~h})$. Equal quantities of proteins were separated on a $12 \%$ SDS-PAGE and after electrophoresis, proteins on the gel were transferred to nitrocellulose membrane and probed with their respective antibodies. $\beta$-actin was used as an internal control. (D) Gallic acid influenced AGS cells apoptosis by pan-caspase inhibitors. AGS cells were treated with gallic acid (5 $\mu M)$ in the presence or absence of the pancaspase inhibitor (Z-VAD-FMK). After 0-72 h of incubation, cells were subjected to the MTT assay. The data represent the mean $\pm S D$ from at least three independent experiments. $* p<0.05 ; * p<0.01$ compared to control.

shown in Figure 4A, gallic acid induced an increase in Fas, FasL, and DR5, but not TRAIL or DR4 expression by Western blot analysis. To further evaluate the roles of Fas, FasL, and DR5 in gallic acid-induced apoptotic signaling in gastric adenocarcinoma cells, Fas, FasL, and DR5 siRNA were used
(Figure 4B). Transfection of cells with Fas, FasL, or DR5 siRNA reduced gallic acid-induced cell apoptosis in AGS cells (Figure 4C). The results suggested that Fas, FasL, and DR5 up-regulation play an important role in gallic acid-induced apoptosis in human gastric adenocarcinoma cells. 

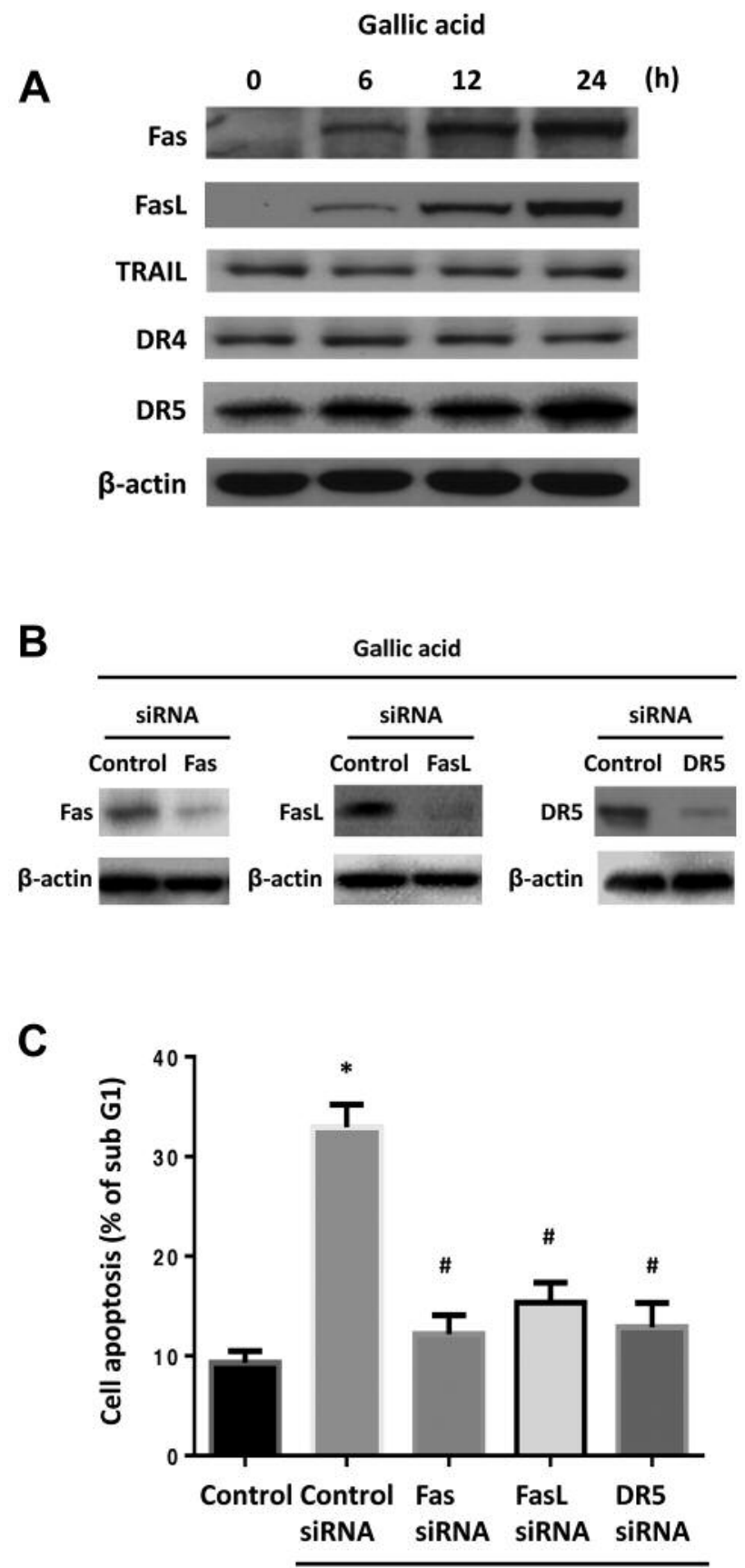

Gallic acid

Figure 4. Extrinsic pathway is involved in gallic acid-induced cell apoptosis in human gastric adenocarcinoma cells. (A) AGS cells were incubated with gallic acid for different time intervals, and the Fas, FasL, TRAIL, DR4, and DR5 expression were examined by western blot analysis. (B) AGS cells were transfected with Fas, FasL, DR5, or control siRNA for $24 \mathrm{~h}$, and Fas, FasL, or DR5 expression was examined by Western blot analysis. (C) AGS cells were transfected with Fas, FasL, DR5, or control siRNA for 24 h, followed by stimulation with gallic acid for $24 \mathrm{~h}$, and the percentage of apoptotic cells was analyzed by flow cytometric analysis of PI-stained cells. Results are expressed as means \pm SEM. ${ }^{*} p<0.05$ compared to control group. $\# p<0.05$ compared to gallic acid-treated group. p53 is involved in gallic acid-induced Fas, FasL, and DR5 up-regulation in human gastric adenocarcinoma cells. It has been reported that $\mathrm{p} 53$, a transcriptional factor, could activate the extrinsic death receptor (DR) signaling pathway. We examined whether p53 was involved in gallic acidinduced cell death in gastric adenocarcinoma cells. Treatment of cells with gallic acid increased $\mathrm{p} 53$ protein expression (Figure 5A). To further investigate whether gallic acid induced apoptosis through p53, we transfected p53 siRNA into AGS cells (Figure 5B). p53 siRNA transfection inhibited gallic acid-induced cell death in AGS cells (Figure 5C). In addition, transfection of cells with p53 siRNA also decreased gallic acid-induced Fas, FasL, and DR5 expression (Figure 5D).

These results suggest that gallic acid inhibits tumor growth by activating apoptosis in AGS cells through the extrinsic pathway while also triggering the intrinsic pathway (Figure 6).

\section{Discussion}

In the present study, we evaluated the anti-cancer activity of Chinese herb Galla chinensis and its main component gallic acid on human gastric adenocarcinoma cells. Among several kinds of herbal extracts, Galla chinensis exerted the most significant effect on the survivability of AGS cells, reducing the survivability of AGS cells to $31.2 \%$ (Table I). We determined that Galla chinensis treatment induces cell death of AGS cells through an apoptotic mechanism.

Gallic acid is the main component of Galla chinensis (38). Galla chinensis contains $50 \%$ to $70 \%$ hydrolyzable tannin, which yields gallic acid. In this study, we demonstrated that gallic acid induces apoptosis in AGS cells, which is in agreement with other studies conducted on other cell lines $(22,30)$.

The process of apoptosis is controlled by two diverse cell signals, which can be initiated by two major pathways: the intrinsic and extrinsic pathways (39). In this study, we evaluated the pathway by which gallic acid mediates apoptosis. Expression of caspase-3 and caspase-9 increased with gallic acid treatment. Expression of anti-apoptosis proteins in the Bcl-2 family was significantly decreased. These results suggest that gallic acid-mediated apoptosis occurs via the intrinsic pathway. This was verified by treating AGS cells with a pan-caspase inhibitor, which abolished gallic acid-induced apoptosis.

Within the extrinsic apoptotic pathway, caspase- 8 is the most proximal caspase that transmits apoptotic signals originating at the membrane death receptors (40). Our study revealed that gallic acid increased the expression and activity of caspase- 8 . This suggests that the extrinsic death receptor pathway is involved in gallic acid-induced cell apoptosis. The extrinsic pathway induces activation of caspase- 8 , and caspase- 3 through 
A

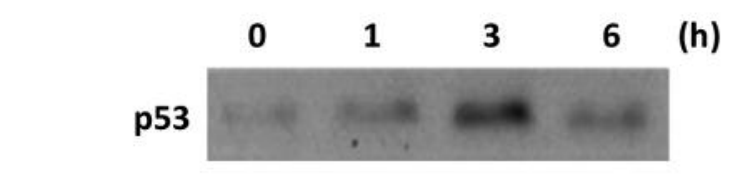

$\beta$-actin

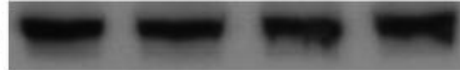

C

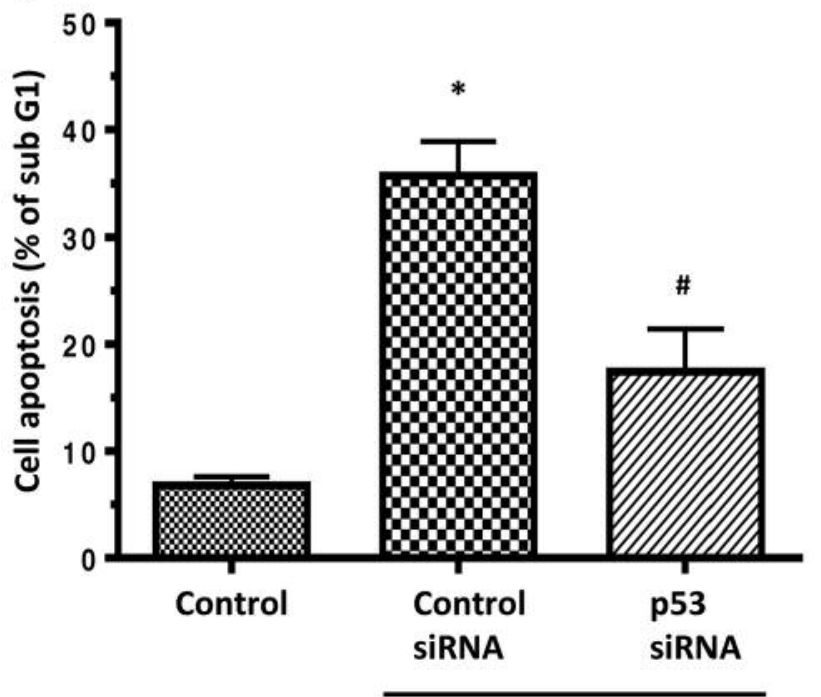

Gallic acid
B

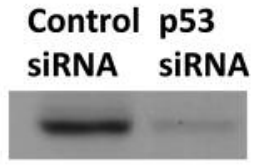

$\beta$-actin

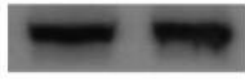

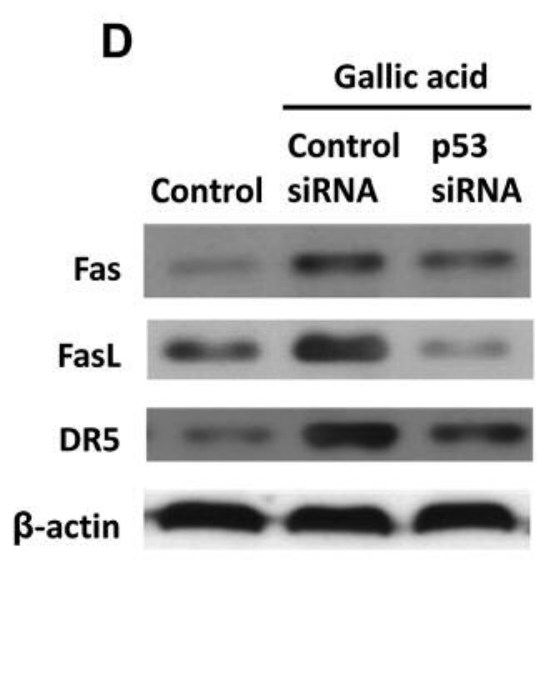

Figure 5. p53 is involved in gallic acid-induced apoptosis in human gastric adenocarcinoma cells. (A) AGS cells were incubated with gallic acid for different time intervals, and 553 expression was examined by western blot analysis. (B) AGS cells were transfected with p53 or control siRNA for 24 h, and p53 expression was examined by western blot analysis. (C) AGS cells were transfected with p53 or control siRNA for 24 h, followed by stimulation with gallic acid for $24 \mathrm{~h}$, and the percentage of apoptotic cells was analyzed by flow cytometric analysis of PI-stained cells. (D) AGS cells were transfected with 553 or control siRNA for 24 h, followed by stimulation with gallic acid for $24 \mathrm{~h}$, and the Fas, FasL, and DR5 expression were examined by Western blot analysis. Results are expressed as means $\pm S E M$. ${ }^{*} p<0.05$ compared to control; \#, $p<0.05$ compared to the gallic acid-treated group .

Table I. Inhibition of AGS growth by fifteen traditional Chinese herbal medicines.

\begin{tabular}{|c|c|c|c|c|}
\hline Chinese name & English name & Pharmaceutical name & Botanical name & Survivability (\%) \\
\hline Da huang & Rhubarb root & Radix et Rhizoma Rhei & R.tanguticum Max.et Baill & $65.8 \%$ \\
\hline Wu bei zi & Galla Chinensis & Gallae Rhois Chinensis & Rhus potaninii Maxim & $31.2 \% * *$ \\
\hline Tian ma & Gastrodia Tuber & Rhizoma Gastrodiae Elatae & Gastrodia elata B1 & $63.6 \%$ \\
\hline Yu xing cao & Houttuynia, pig thigh & Herba cum radice houttuyniae cordatae & Tis chinesis & $72.2 \%$ \\
\hline Huang lian & Coptis rhizome & Rhizoma Coptidis & Coptis chinensis Franch & $49.2 \% *$ \\
\hline Di yu & Official burnet root & Radix Sanguisorbae officinalis & Sanguisorba officinalis L. & $77.6 \%$ \\
\hline Shan yao & Chinese wild yam & Radix Dioscoreae Oppositae & Dioscorea opposita Thunb. & $78 \%$ \\
\hline Xian he cao & Hairyvein Agrimonia Herb & Herba Agrimoniae & Agrimonia pilosa Ledeb & $67.7 \%$ \\
\hline Dan shen & Salvia root & Radix Salvia miltiorrhizae & Salvia miltiorrhiza Bge & $71.4 \%$ \\
\hline Mu xiang & Costus root & Radix Aucklandiae & Aucklandia lappa Deene & $70.9 \%$ \\
\hline Jie geng & Root of balloon flower & Radix Platycodi grandiflori & Platycodon grandiflorum & $74.7 \%$ \\
\hline San qi & Notoginseng root & Radix Notoginseng & Panax Notoginseng & $55.1 \% *$ \\
\hline Ban lan Gen & Indago woad root & Radix Isatidis seu Baphicacanthi & Baphicacanthus cusia(Nees)Brem & $75.9 \%$ \\
\hline Shan zhu yu & Asian Cornelian Cherry Fruit & Fructus corni officinalis & Cornus officinalis Sieb. et Zucc & $80.3 \%$ \\
\hline Shen qu & Medicated leaven & Medicata Fermentita Fujianensis Massa & Shinkyoku & $87.7 \%$ \\
\hline
\end{tabular}

${ }^{*} p<0.05 ;{ }^{* *} p<0.01$. 


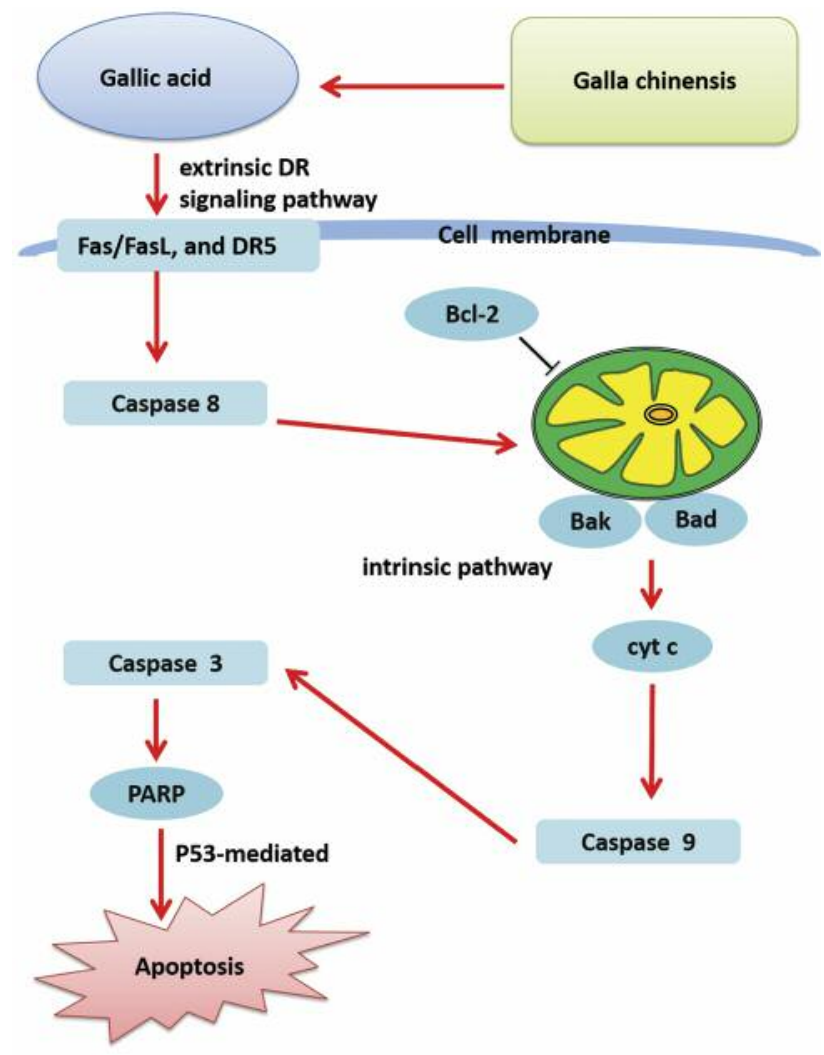

Figure 6. Gallic acid activates apoptosis in human gastric adenocarcinoma cells through the extrinsic pathway while also triggering the intrinsic pathway.

DRs (40). The interaction between Fas and FasL results in the formation of the death-inducing signaling complex, which contains the FADD and caspase-8. We demonstrated that gallic acid increased Fas and FasL expression. The transfection of cells with Fas or FasL siRNA reduced gallic acid-increased cell apoptosis. Therefore, Fas and FasL were shown to be involved in gallic acid-induced cell death.

In this study, we also examined the expression of DR4 and DR5 after gallic acid treatment. The data indicate that gallic acid increased the expression of DR5, but not DR4 in human gastric adenocarcinoma cells. TRAIL has been shown to induce apoptosis by activating caspase- 8 via its receptors DR4 and/or DR5 (41). Recent studies indicate that DR levels can be enhanced by endogenous induction or exogenous overexpression. Several genotoxic and non-genotoxic agents can induce apoptosis by increasing endogenous DR5 (42). We demonstrated that gallic acid-induced apoptosis was coupled with DR5 induction without changes in the expression of its ligand, TRAIL. It is possible that gallic acid activated DR5 to induce cell death in a ligand-independent manner. The transfection of cells with DR5 siRNA reduced gallic acid- induced cell death. Therefore, DR5 also appears to be involved in gallic acid-increased cell apoptosis in human gastric adenocarcinoma cells. In this study, gallic acid induced Fas, FasL, and DR5 beginning at around $6 \mathrm{~h}$ and peaking at $24 \mathrm{~h}$, while p53 was up-regulated at 1 to $3 \mathrm{~h}$ and returned to the basal level by $6 \mathrm{~h}$. The transfection of cells with p53 siRNA decreased gallic acid-induced Fas, FasL, and DR5 expression. Consequently, p53 expression is an upstream molecule in gallic acid-induced Fas, FasL, and DR5 expression as well as cell apoptosis in adenocarcinoma cells.

Recently, several studies focused on advanced gastric cancer with severe peritoneal metastasis. Nanoparticle albumin-bound (nab)-paclitaxel, a new class of anticancer agent that allows for a safe infusion of significantly higher doses of paclitaxel, have been proven safe and beneficial for advanced/recurrent gastric cancer patients (43). 5-FU/LV plus oxaliplatin (FOLFOX) was found effective and manageable as first-line treatment for advanced gastric cancer patients with massive ascites and/or inadequate oral intake due to severe peritoneal metastasis (44). The results of this study provide evidence for the molecular basis of the apoptotic effect of gallic acid in gastric cancer cells for the first time. The key targets mediated by gallic acid could serve as potential therapeutic targets. Also, gallic acid has been shown to exert anti-metastasis effects on gastric cancer cells (45). Together, these findings suggest that gallic acid may be a novel anticancer agent against advanced gastric cancer with peritoneal metastasis.

In conclusion, we demonstrated that gallic acid can induce apoptosis via the extrinsic death receptor pathway/intrinsic pathway. These data may be helpful in developing a regimen with the potential to treat gastric cancer.

\section{Conflicts of Interest}

The Authors declare no conflicts of interest.

\section{Acknowledgements}

This work was supported by a Grant from the Changhua Christian Hospital, Changhua, Taiwan (106-CCH-IRP-055).

\section{References}

1 Ferlay J, Soerjomataram I, Dikshit R, Eser S, Mathers C, Rebelo M, Parkin DM, Forman D and Bray F: Cancer incidence and mortality worldwide: Sources, methods and major patterns in globocan 2012. Int J Cancer 136(5): E359-386, 2015.

2 Fontana E and Smyth EC: Novel targets in the treatment of advanced gastric cancer: A perspective review. Ther Adv Med Oncol 8(2): 113-125, 2016.

3 Kuo HW, Huang CY, Fu CK, Liao CH, Hsieh YH, Hsu CM, Tsai CW, Chang WS and Bau DT: The significant association of ccnd1 genotypes with gastric cancer in taiwan. Anticancer Res 34(9): 4963-4968, 2014. 
4 Kuo WH, Huang CY, Fu CK, Hsieh YH, Liao CH, Hsu CM, Huang YK, Tsai CW, Chang WS and Bau DT: Effects of interleukin-10 polymorphisms and smoking on the risk of gastric cancer in taiwan. In Vivo 28(5): 967-971, 2014.

5 Yang M-D, Wang H-C, Chang W-S, Tsai C-W and Bau D-T: Genetic polymorphisms of DNA double strand break gene ku70 and gastric cancer in taiwan. BMC Cancer 11(1): 174, 2011.

6 Ji HX, Chang WS, Tsai CW, Wang JY, Huang NK, Lee AS, Shen MY, Chen WY, Chiang YC, Shih TC, Hsu CM and Bau DT: Contribution of DNA repair xeroderma pigmentosum group $\mathrm{d}$ genotype to gastric cancer risk in taiwan. Anticancer Res 35(9): 4975-4981, 2015.

7 Jiao L, Bi L, Lu Y, Wang Q, Gong Y, Shi J and Xu L: Cancer chemoprevention and therapy using chinese herbal medicine. Biol Proced Online 20: 1, 2018.

8 Hassan M, Watari H, AbuAlmaaty A, Ohba Y and Sakuragi N: Apoptosis and molecular targeting therapy in cancer. Biomed Res Int 2014: 150845, 2014.

9 Elmore S: Apoptosis: A review of programmed cell death. Toxicol Pathol 35(4): 495-516, 2007.

10 Parrish AB, Freel CD and Kornbluth S: Cellular mechanisms controlling caspase activation and function. Cold Spring Harb Perspect Biol 5(6): a008672, 2013.

11 Parrales A and Iwakuma T: Targeting oncogenic mutant p53 for cancer therapy. Front Oncol 5: 288, 2015.

12 Vijayakumaran R, Tan KH, Miranda PJ, Haupt S and Haupt Y: Regulation of mutant p53 protein expression. Front Oncol 5: 284,2015

13 Henry RE, Andrysik Z, París R, Galbraith MD and Espinosa JM: A dr4:Tbid axis drives the p53 apoptotic response by promoting oligomerization of poised bax. EMBO J 31(5): 1266-1278, 2012.

14 Kantari C and Walczak H: Caspase- 8 and bid: Caught in the act between death receptors and mitochondria. Biochimica et Biophysica Acta (BBA) - Mol Cell Res 1813(4): 558-563, 2011.

15 Agarwal C, Tyagi A and Agarwal R: Gallic acid causes inactivating phosphorylation of $\operatorname{cdc} 25 \mathrm{a} / \mathrm{cdc} 25 \mathrm{c}-\mathrm{cdc} 2 \mathrm{via}$ atmchk2 activation, leading to cell cycle arrest, and induces apoptosis in human prostate carcinoma du145 cells. Mol Cancer Ther 5(12): 3294-3302, 2006.

16 Faried A, Kurnia D, Faried LS, Usman N, Miyazaki T, Kato H and Kuwano $\mathrm{H}$ : Anticancer effects of gallic acid isolated from indonesian herbal medicine, phaleria macrocarpa (scheff.) boerl, on human cancer cell lines. Int J Oncol 30(3): 605-613, 2007.

17 Inoue M, Suzuki R, Sakaguchi N, Li Z, Takeda T, Ogihara Y, Jiang BY and Chen Y: Selective induction of cell death in cancer cells by gallic acid. Biol Pharm Bull 18(11): 1526-1530, 1995.

18 Inoue M, Suzuki R, Koide T, Sakaguchi N, Ogihara Y and Yabu Y: Antioxidant, gallic acid, induces apoptosis in hl-60rg cells. Biochem Biophys Res Commun 204(2): 898-904, 1994.

19 Isuzugawa K, Inoue M and Ogihara Y: Catalase contents in cells determine sensitivity to the apoptosis inducer gallic acid. Biol Pharm Bull 24(9): 1022-1026, 2001.

20 Ji BC, Hsu WH, Yang JS, Hsia TC, Lu CC, Chiang JH, Yang JL, Lin CH, Lin JJ, Suen LJ, Gibson Wood W and Chung JG: Gallic acid induces apoptosis via caspase-3 and mitochondriondependent pathways in vitro and suppresses lung xenograft tumor growth in vivo. J Agric Food Chem 57(16): 7596-7604, 2009.

21 Kang MS, Oh JS, Kang IC, Hong SJ and Choi CH: Inhibitory effect of methyl gallate and gallic acid on oral bacteria. J Microbiol 46(6): 744-750, 2008.
22 Kaur M, Velmurugan B, Rajamanickam S, Agarwal R and Agarwal C: Gallic acid, an active constituent of grape seed extract, exhibits anti-proliferative, pro-apoptotic and antitumorigenic effects against prostate carcinoma xenograft growth in nude mice. Pharm Res 26(9): 2133-2140, 2009.

23 Kawada M, Ohno Y, Ri Y, Ikoma T, Yuugetu H, Asai T, Watanabe M, Yasuda N, Akao S, Takemura G, Minatoguchi S, Gotoh K, Fujiwara H and Fukuda K: Anti-tumor effect of gallic acid on 11-2 lung cancer cells transplanted in mice. Anticancer Drugs 12(10): 847-852, 2001.

24 Kim SH, Jun CD, Suk K, Choi BJ, Lim H, Park S, Lee SH, Shin HY, Kim DK and Shin TY: Gallic acid inhibits histamine release and pro-inflammatory cytokine production in mast cells. Toxicol Sci 91(1): 123-131, 2006.

25 Veluri R, Singh RP, Liu Z, Thompson JA, Agarwal R and Agarwal C: Fractionation of grape seed extract and identification of gallic acid as one of the major active constituents causing growth inhibition and apoptotic death of du145 human prostate carcinoma cells. Carcinogenesis 27(7): 1445-1453, 2006.

26 Atkinson BL, Blackman AJ and Faber H: The degradation of the natural pyrethrins in crop storage. J Agric Food Chem 52(2): 280-287, 2004

27 Chakraborty A, Ferk F, Simic T, Brantner A, Dusinska M, Kundi M, Hoelzl C, Nersesyan A and Knasmuller S: DNA-protective effects of sumach (rhus coriaria 1.), a common spice: Results of human and animal studies. Mutat Res 661(1-2): 10-17, 2009.

$28 \mathrm{Ng}$ TB, He JS, Niu SM, Zhao L, Pi ZF, Shao W and Liu F: A gallic acid derivative and polysaccharides with antioxidative activity from rose (rosa rugosa) flowers. J Pharm Pharmacol 56(4): 537-545, 2004.

29 Shahrzad S, Aoyagi K, Winter A, Koyama A and Bitsch I: Pharmacokinetics of gallic acid and its relative bioavailability from tea in healthy humans. J Nutr 131(4): 1207-1210, 2001.

30 Chia YC, Rajbanshi R, Calhoun C and Chiu RH: Anti-neoplastic effects of gallic acid, a major component of toona sinensis leaf extract, on oral squamous carcinoma cells. Molecules 15(11): 8377-8389, 2010.

31 Yeh RD, Chen JC, Lai TY, Yang JS, Yu CS, Chiang JH, Lu CC, Yang ST, Yu CC, Chang SJ, Lin HY and Chung JG: Gallic acid induces $\mathrm{g}(0) / \mathrm{g}(1)$ phase arrest and apoptosis in human leukemia hl-60 cells through inhibiting cyclin $\mathrm{d}$ and $\mathrm{e}$, and activating mitochondria-dependent pathway. Anticancer Res 31(9): 28212832, 2011

32 Subramanian AP, Jaganathan SK, Mandal M, Supriyanto E and Muhamad II: Gallic acid induced apoptotic events in hct-15 colon cancer cells. World J Gastroenterol 22(15): 3952-3961, 2016.

33 Peng CC, Hsieh CL, Wang HE, Chung JY, Chen KC and Peng RY: Ferulic acid is nephrodamaging while gallic acid is renal protective in long term treatment of chronic kidney disease. Clin Nutr 31(3): 405-414, 2012.

34 Fiuza SM, Gomes C, Teixeira LJ, Girao da Cruz MT, Cordeiro MN, Milhazes N, Borges F and Marques MP: Phenolic acid derivatives with potential anticancer properties - a structureactivity relationship study. Part 1: Methyl, propyl and octyl esters of caffeic and gallic acids. Bioorg Med Chem 12(13): 3581-3589, 2004.

35 Wu YY, Tsai HF, Lin WC, Hsu PI, Shun CT, Wu MS and Hsu PN: Upregulation of ccl20 and recruitment of ccr6+ gastric infiltrating lymphocytes in Helicobacter pylori gastritis. Infect Immun 75(9): 4357-4363, 2007. 
$36 \mathrm{Wu}$ YY, Tsai HF, Lin WC, Chou AH, Chen HT, Yang JC, Hsu PI and Hsu PN: Helicobacter pylori enhances tumor necrosis factor-related apoptosis-inducing ligand-mediated apoptosis in human gastric epithelial cells. World J Gastroenterol 10(16): 2334-2339, 2004.

37 Chandramohan Reddy T, Bharat Reddy D, Aparna A, Arunasree KM, Gupta G, Achari C, Reddy GV, Lakshmipathi V, Subramanyam A and Reddanna P: Anti-leukemic effects of gallic acid on human leukemia k562 cells: Downregulation of cox-2, inhibition of bcr/abl kinase and nf-kappab inactivation. Toxicol In Vitro 26(3): 396-405, 2012.

38 Huang X-L, Liu M-D, Li J-Y, Zhou X-D and ten Cate JM: Chemical composition of galla chinensis extract and the effect of its main component(s) on the prevention of enamel demineralization in vitro. Int J Oral Sci 4(3): 146-151, 2012.

39 Ichim G and Tait SWG: A fate worse than death: Apoptosis as an oncogenic process. Nat Rev Cancer 16: 539, 2016.

40 Park C, Hong SH, Kim G-Y and Choi YH: So-cheong-ryongtang induces apoptosis through activation of the intrinsic and extrinsic apoptosis pathways, and inhibition of the pi3k/akt signaling pathway in non-small-cell lung cancer a549 cells. BMC Complement Altern Med 15: 113, 2015.

41 Fossati S, Ghiso J and Rostagno A: Trail death receptors dr4 and dr5 mediate cerebral microvascular endothelial cell apoptosis induced by oligomeric alzheimer's a $\beta$. Cell Death Dis 3: e321, 2012
42 Tsai A-C, Pan S-L, Sun H-L, Wang C-Y, Peng C-Y, Wang S-W, Chang Y-L, Kuo S-C, Lee K-H and Teng C-M: Chm-1, a new vascular targeting agent, induces apoptosis of human umbilical vein endothelial cells via p53-mediated death receptor 5 upregulation. J Biol Chem 285(8): 5497-5506, 2010.

43 Kanazawa Y, Fujita I, Kakinuma D, Arai H, Matsuno K, Shimoda T, Ko K, Kato S and Uchida E: Initial experience with nab-paclitaxel for patients with advanced gastric cancer: Safety and efficacy. Anticancer Res 37(5): 2715-2720, 2017.

44 Masuishi T, Kadowaki S, Kondo M, Komori A, Sugiyama K, Mitani S, Honda K, Narita Y, Taniguchi H, Ura T, Ando M, Mishima $\mathrm{H}$ and Muro K: Folfox as first-line therapy for gastric cancer with severe peritoneal metastasis. Anticancer Res 37(12): 7037-7042, 2017.

45 Ho HH, Chang CS, Ho WC, Liao SY, Wu CH and Wang CJ: Anti-metastasis effects of gallic acid on gastric cancer cells involves inhibition of nf-kappab activity and downregulation of pi3k/akt/small gtpase signals. Food Chem Toxicol 48(8-9): 25082516,2010

Received December 25, 2017

Revised January 30, 2018

Accepted February 1, 2018 